est in the more radical method until a few men began to express dissatisfaction with the general run of results, as shown in earlier times. My dependence is on the $x$-ray find ings rather than on the.so-called clinical methods of diagnosis. With regard to technic it is to be insisted that what one man can do uniformly well, another man cannot do at all, and the latter does not need very wide experience to prove that ho camnot do this work well. I am not insistent on the value of one or another material or appliance with which to secure fixation. I emplatically do not concur in the statement that the Lane plate is the sine qua non in the operative treatment of fractures. If I use a Lane plate, I select the smallest one possible and I employ the staple more frequently than the plate. It is to be insisted on that neither the plate nor any other fixation appliance is, in any sense, a splint. Axial relation is not to be maintained by fixation material. The function of fixation material is closely analogous to the stiteh in the garment. The main thing to be accomplished by the staple or plate or wire or nail is temporary fixation. Subsequent alignment is to be maintained by. a properly adjusted plaster-of-Paris dressing. In fructures of the thigh; after the introduction of a plate or staple, the limb is to be immobilized by a plaster spica extending from the short ribs to the foot. As soon as the plaster is hardened, I find it advisable to remove the entire roof of the plaster dressing from the toes to the waist, allowing the patient to lie in the trough which is made up of the posterior segment of the original splint. This gives splendid opportunity for maintenance of nutrition of the limb and immediate access to the seat of fracture. The advantages llowing therefrom are perfectly obvious. I am going to make a prophecy, that, within the next twelve, eighteen or twentyfour months, we are going to hear less said about placing foreign bodies in infected fractures. You might as well try to drive bedbugs out of a $\log$ cabin as to attempt to sterilize an infected wound at one or several sittings. Suppose you have an infected wound and you have adjusted the fracture accurately, and have used every possible effort to disinfect the wound, there is one place where we cannot be sure of having secured asepsis, and that is, between the fragments, the most important point. You have shut up the infected material in " closed cavity and produced a condition which is productive of disastrous results. In the future, we will sacrifice axial relation rather than attempt to complicate the case by the jutroduction of a splint in a permanently infected bone cavity.

Dr. Willakd BartletT, St. Louis: I never fail to profit by Dr. Ochsner's criticism, and after hearing him say what he did I am forced to the conclusion that there must have been something wrong with the reading of my paper, because lie thoroughly misunderstood me, and he sat only 30 feet away.

DR. F. J. Cotron, Joston: It seems to me that we cannot fairly condemn the use of all plates in bone fructures. There are after all many cases in which it seems worth while to rum the risk of foreign-body sepsis in order to effect and maintain reduction. I do not use the Lane plate in the majority of $m y$ cases, because no matter how good a rigid plate is, it necessurily exposes the patient to the danger of pulling out the serews. I have seen that happen and have also seen tise Lane plate itself fracture. It seems to me that much is to be said in favor of a slightly flexible elastic plate, one which can be fitted to the case in hand, and which allows of the use of a smaller plate, if necessary, especially in fractures of the femur. Whether this plate is made of aluminum or phosphor-bronze or silver or wrought iron does not make any difference, but $I$ think that a slightly elastic plate slould be used. I lave been disappointed that no one took up what I said about the presence of synovial fluid in intracapsular fracture. It has been said that we must always secure contact of the fragments, but no one referred to the exclusion of the synovial fluid, and that, in my opinion, is most necessary to secure clot and callus between the bones. Reasonable contact without such exclusion may often be insufficient.

Dr. William Darrach, New York: I agree with Dr. Cotton that a slightly flexible plate is better than an absolutely stiff one. I think that the vanadium steel plate is the ideal one. Most plates kept in stock do not fit, and therefore ono slionld also have at hand some material which can be molded to fit. We ought to lave more detailed reports of cases because it is only in that way that one can learn the end. results in these cases, say after six months or, better, two years. Then we can compare the newer methods with the older ones, the open treatment with the closed treatment. I hope that my paper did not convey the idea that these operation are ensy, becuuse they are not.

1Dr. Lhonard W. Ely, Denver: Clinical observation is the final court of appeal! This final court of appeal has been handing down its infallible decisions for thousunds of years. They are received without question, until some obscure pathologist in the privacy of his laboratory examines them under the mieroscope, and they are laughed out of court. Clinical observation teaches millions of people in this country that they can cure all disease by dilutions of powdered sugar, millions more that they can cure all disease by tinkering with the spine, and millions more that they can cure all diseaso by denying its existence. It teaches one thing to-day and another-to-morrow. Clinical observation is not the final court of appeal. It is an advocate before the bar, and when the advocate usurps the functions of the judge, and hands down decisions contrary to the evidence of sound pathology, we have a remedy-the recall.

\section{CONSTIPATION AND HEADACHE IN WOMEN}

\section{A STUDY IN EITOLOGY AND DIAGNOSIS *}

CHARLES A. I. REED, M.D.

Professor in the University of Cincinnati cincinnati

The frequent occurrence of constipation and headaches in women is a matter of daily observation by every practitioner. The almost constant occurrence of these two symptoms in connection with painful menstruation, tender ovaries and uteri that are more or less displaced has led to the general conclusion that these conditions are the actual causes of the constipation and headaches. We have heard much in times past of "reflex lieadaches" and of "constipation due to the pressure of a displaced uterus on the reetum." We have likewise seen many of these cases in which the constipation and the headaches lave gone on even with increasing severity, after the conditions within the pelvis had been corrected.

I am now seeing a certain important number of cases in which the pelvic symptoms, with the constipation and headaches, disappear after the cure of the conditions of the stomach and intestines, on which the constipation and hendaches depend. It would seem, there. fore, as if, in these certain cases, the original proposition would have to be reversed and that we are henceforth to look on the displacements and functional disturbances of the uterus and ovaries as being caused by, rather than being the cause of, conditions of the stomach and intestines to which $\mathrm{I}$ am about to allude.

The theory is not new. It was in 1885 that the researches by Glenard ${ }^{1}$ established the following facts, viz.: 1. Downward displacement of the stomach and intestines, both large and small, is of frequent occurrence. 2. Such displacements give rise to mechanical obstruction of (a) the fecal current, (b) the mesenteric and other visceral circulation of the blood, and (c) the chyle and lymph currents. 3. The mechanical obstrue-

* Read in the Section on Obstetrics and Gynecology of the Amer. Ican Medical Assoctation. ut its Sixty-Thlrd Annual Session, beld at Atlantic Clty, June, 1812.

1. Glenard, Franz: I,es Ptoses Viscérales, Paris, 1899. Thls embraces the communication by the same author published originally
in the Isyon Medical, March, April, $\mathbf{1 8 8 5}$. 
tion, of various degrees, in the intestinal tract not only causes serious disturbances of digestion in both the stomach and intestines, but causes likewise the phenomena of constipation with resulting hyperabsorption of toxins that are physiologically elaborated in the prima via. 4. The absorption of such toxins causes healaclies, nervousness, mental depressions and numerous other phenomena often grouped in the clinical picture of neurasthenia. 5. The downward displacement of the intestines implies that their weight and the weight of their contents rest on the underlying uterus, ovarics, fallopian tubes and other pelvic organs. 6. Such superimposed weight and pressure, and the circulatory disturbances to which I have alluded cause mechanical congestion and more or less marked displacement, with jesulting pain, tenderness and functional disturbance of the uterus and ovarjes.

That intestinal displacements, considered as causes, not only of constipation and headaches in both sexes, but of pelvice disturbances in women, are often overJooked is established by the histories of many cases now and latterly occurring in my practice, muny-practically all-of which have been under treatment previously for conditions of the uterus and ovaries. T)isplacements of the nterus lave generally been corrected by necessory operative interference, witlout which recovery under any eircumstances would lave been impossible. Gross organic changes-such as growths and degererations of either the uterus or ovaries, or hoth - may have been removed, and athesions, the traces of previous inflammatory disturbance, may have been broken up. Tacerations of the cervix or perineum, or both, may have been repaired. In short, all strictly gynecolngic indications may have been met, without amelioration of either the constipation or the headaches that existed before operation. Then, whatever may have been the treatment preceling surgical interference, the patient is started on another jound of expericnees. First, from sheer necessity she is given catharties, with or without high injections, as the necessary means of temporary relief. Those who can afford it start on a tour of the watering places. where, in addition to laxatives, they employ baths and massage, which seem to help while they are liept up.

Those who cannot afford to travel, but must earn their living, stay liome and take pills, salts and injections. These, too, help or seem to help for a time, each dose, however, increasing the necessity for still other doses. At about this stage, full symptomatology becomes developed.

\section{SYMTPTOMS}

When treatment of this character is interrupted. there js generally a prompt relapse. Not only do the constipation and licadaches, but the nterine and ovarian symptoms, if they have been relieved at all, resume their original severity. In addition, there is pain in the back, especially ligh up in the loins, and occurring with more frequeney on the left side. There is liable to be a distinct complaint of pain at the lower end of the spine, radiating thence lown one or both thigls. In front, on the right side, there are two listinct locations, to one or both of which pain is frequently almost constantly refered. One of these is the right lower quadrant in the neighborhood of the appendix vermiformis; the other is in the right upper quadrant near the lower margin of the liver. Pain in these localities may, or may not, be constant; it may be of a dull, aching character, or, as frequently happens, it may become severely colicky. These colicky pains in the neiglbborhood of the appendix are often so sudden in onset, ec intense in severity, so definite in location, and are associated with such rigid, local, muscular resistance as to simulate appendicitis. So often has this occurred in my practice, that, in the absence of temperature disturbance, I have come to designate the condition as "pseudo-appendicitis." So marked is tlie resemblance to true appendicitis that the diagnosis cannot be established without surgical interference, which, in such cases, ought to be done to give the patient the bencfit of the doubt.

On the left side, in front, pain of the same character is often in the upper quadrant at a point corresponding to the point of greatest persistence of pain in the back. There is more or less of discomfort in the lower zone of the aldomen, which may be tympanitic, especially in the left side. The blather may be irritated, as shown by frequent desire to minate. Digital examination with the patient standing will always show either a displace. ment of the uterus, or the presence of a superimposed weight, tending to lorce it into a state of displacement. At the same time, the complexion is generally bad, there is a tendency to slecplessness and nervous irritability, there is liable to be some irregularity of the heart, digestion is upset, there is often loss of flesh, and almost constantly there is a loss of energy, associated with mental depression.

\section{DIAGNOSIS}

These symptoms are sufficient to establish a presumptive diagnosis of displacement of the stomach, or of the colon, or of both. But, fortunately, it is rot necessary that the dingnosis of these necessarily remote and elusive or wans should be merely "presumptive." It can be placed absolutely in the positive class, either by the $x$-ray, or by an exploratory operation. If the $x$-ray is employed, an excellent instrument and a skilled operator are necessary to secure reliable results. When they are employed, in the cases indicated, some of the recognized departures from the normal stanclard of position will be found in the stomach, the colon, the sigmoid, or the suall intestines, or all of them. The stomach is very likely to be shown as occupying a very decided vertical position in the lelt sicle of the abrominal cavity with more or loss pronounced angulation of the pylorus, which lies well down in the left iliac fossa. It should be remembered, however, that a stomach occupying this position, when normally laden, may lave the power of emptying itself with physinlogic promptness and of regaining its normal position when thus emptied. The peristaltic waves may sometimes be demonstrated. It follows, therefore, that the so-called tubular stomach, one demonstrated to be oreupying the position that I have indicated, should not be consirlered pathologic unless gastric symptoms, clearly cxplaingble by and traceable to the displacement, comprise a fenture of the case.

The position of the small intestines can sometimes be approximately determined by shadowy floceuli a few loours after the bismuth has been given, and after it has had time to make the descent. The perfection of the Rocntgen technic will doubtless shortly enable us to determine this phase of these cases with more precision than is now possible. In the matter of the colon, however, present revelations are most striking, accurate and detailed. It is inportant, however, for the proper interpretation of the plates thus made to understand what comprises tlie normal and what an abnormal condition of the colon, and especially the transverse segment of the colon. No hard and fast locus can be defined as explicitly normal. Ample a-ray pictures show, however, 
that the normally laden colon extends directly upward from the cccum along the right side to the so-called liepatic flexure, thence along the right costal margins obliquely upward and across to the splenic flexure on the opposite side, and thence vertically downward to the sigmoid. Plates given in the conventional anatomies showing a horizontally transverse colon are erroneous and misleading.

Departures from this approximately normal standard are numerous and of varying degree. The usual displacement, however, consists of a gencral descent by which the cecum finds its way low into the pelvis. 'I'here is a corresponding lowering of the hepatic flexure of ten below the level of the anterior, superior spinous process, then a sharp dropping of the transverse colon producing obstructive angulation at the hepatic flexure. The transverse colon mav be redundant and folded on itself, thus producing one or more additional angles of resistance. It then swreeps up to the splenic flexure, which point of fixation is but rarely disturbed, but at which, in these cases, another acute angle of resistance is formed. There may, or may not be similar redundancies and folding of the sigmoid, thus giving rise to other points of retardation.

In certain cases, it is easy to read in the $x$-ray plate that, in addition to the displacements already indicated, there exists a constriction of the ascending colon, due to a long-standing pericolitis with consequent formation of Jackson's membrane. It is frequently possible. by the same means, to tell whether or not there are adhesions between the proximal surfaces of the intestines, or between the intestinal and other peritoneal surfaces.

A study of the diagnostic points shows that they may be, and histories given by my patients show that they are, frequently misinterpreted. Gastric ulcer, gastritis, dundenal ulcers and pyloric cicatrices are the conditions most generally confused with gastroptosis. Appendicitis, gall-stones, renal colic, infections of the fallopian tubes and troplic or inflammatory disturbances of the ovaries ure the conditions most generally confused with displacement of the colon. $\AA$ carefil study of the symptoms of gastrocoloptosis as given, remembering that they comprise a rather definite complexity, will cnable the examiner to arrive at a presumptive diagnosis by exclusion. The question is, of course, promptly settled by the $x$-ray.

I wish to he emplatic in the statcment that not all departures from what I have indieated as the approximate uormal standard are attended with or followed by symptoms of disease. On the contrary, certain deviations, some of them associated with apparent angulation, seem to be compatible with a fair degree of health. It is only in those cases in which, with displacements demonstrated with the $x$-ray, there exists such associated and logically sequent conditions as habitual constipation, painful peristalsis, headaches, nervousness, mental heletude, lessened efficiency and other evidences of toxemia, or in which several of these conditions are found to coexist with constipation - I say it is only in such cases that we are justified in looking on the case as one calling for" surgical interference.

Now that I have made this point clear, let me rcsime the thread of my abservations by stating that the displacements of the intestines such as I have indicated, when pathologie in degree and effect, are always associated with distinct retardation of the fecal recurrent, and with the consequent inevitable hyperabsorption of toxins. This retardation as shown by repeated $x$-ray pictures occurs first in the cecum, next at the hepatic flexure, next at any point of acute angulation that may exist in the redundant and angulated transverse colon, next at the splenic flexure and finally in the sigmoid. My observations, based on nearly two hundred diagnosed cases, show that the transit through the colon may be retarded all the way from a few liours to five days. I have no doubt that cases have been observed by other prectitioners in which an even longer period of transit has been demonstrated. The fact, as shown, that this retardation occurs at the successive point of angulation is conclusive evidence that the angulation is responsible for the retardation. 'The frequency with which the diagnostic importance of these symptoms has been, and is being, confirmed by surgical exploration at my hands and at the lands of others impresses me that they comprise a more or less definite syndrome. The uniformity with which the conditions thus revealed are overcome either by actual correction or by compensatory operation, and the almost equal uniformity with which such treatment is followed by cure, both local and constitutional, convinces me that intestinal displacements are at least frequent causes of pelvis mischief and general disturbances of health in women, and that the cure of such intrapelvic conditions must logically depend on the cure of the underlying causative conditions in the stomach and intestines.

Groton Building.

\section{ABSTRACT OF DISCUSSION}

Dr. Richard R. Smitu, Grand Rapids: In a general way I quite agree with Dr. Reed's conclusions as to the relationship of the pelvic disorders to intestinal displacement. I think we can hardly trace any particular connection between the two. We would naturally think that pelvic displacements would be associuted with displacements in the abdomen and vice versa. As a matter of fact, we have lard work to find any particular relationship. l'rolnpse of the uterus is to-day properly regarded as a hernia and has about the same relation to intestinal displacement as any other abdominal hernia, and that is practically none. With retroversion, on the other hand, we might suppose that the change in axis of the pelvic cavity so often found associated with visceral prolapse would have some infuence in displacing the fundus backward. If we investigate the matter, we do not find that this ocenrs with sufficient regularity to justify any such supposition; so we may say that, anatomicully at least, there is no apparent relationship between the pelvie and the abdominal displacements. The group of symptoms so frequently spoken of-backache, pain in the side, a fecling of weight and beuring down, with disturbance of the functions of menstruation, digestion and minution and in long list of psychic disturbunces -we may find when we have displacements of the abdominal organs, or of the pelvic organs, or both. I am not willing to accept Dr. Reed's rather wide-spread conchusions as to the relationship between the prolapse that we find and the symptoms which we find associated with it. Certainly women with the most murked prolapse of ten lave practicully no symptoms. On careful study we shall find, I believe, that in the mujority of cases the symptoms are due to another cause, usually a fatigue neurosis. This would not cover all the cases but the great majority, and I think we nust be most careful in sepurating from this general group the eases in which the displacement itself actually causes symptoms; otherwise, we shall be inclined to treat surgically many patients who will not be benefited but perhaps made worse.

DR. J. H. Cars'rens, Detroit: What is back of all this tronble? These poor women are born wrong with the reluxed conditions of all the organs. Not only that, but to a great extent they are made so by their mode of living. A girl who is slim and thin studies, goes to school and thumps the piano three or four hours a day; perhaps she is poor; perhaps lee 
ancestors were seventeen generations of the man with the hoe. She has a poor brain, but one attribute of the mindumbition. She wants to be a school teacher, or a stenog. rapher, but she has not the mental ability to grusp thoughts quickly. As a result she studies hard, sits on her chair all day and does not exercise. That is the great trouble at the bottom of the whole thing. Take the girls of that type when they are 10 or 12 years old snd make tom-boys out of them and they will not suller like that. It is not a question of doing this or that operation, but $n$ question of wrong physiology. We do not take hold of those.girls early and make them take physieal exercise so that they develop their muscles and nerves and get strong abdominal organs that will stay in place. That is what we have to do for the treatment. Sone of these people have colons hanging away down with angulations. A woman came to see ne the other vay with auto-intoxication-absorption. Why? Because she does not live a physiologienlly correct life. I have figured that whe drinks one pint of liquikl in a day. How in the name of common sense do you expect the liver to curry on metab. olism? How do you suppose the bowels will move if there is no more liquid to carry on the work? Let the woman drink four pints of liquid a day. Then there will be metab. olism and no auto-intoxication. Let us have " little more physiology!

j)R. JABEz N. JACKson, Kansas City, Mo.: It is rather evident to me that Dr. Smith and Dr. Carstens have failed entirely to grasp tlec fundamentul facts as presented by Dr. Reed. In the first place, I take it that 1)r. Reed has mado no reference whatsoever to the displacements of the pelvic orguns of women, but rather to pelvic conditions dependent on displacement of the intestinal structures. Jr. Carstens has talked a good deal about the necessity of preserving more of the physiologic function of the woman. Any one who has observed the displacements covered by Jr'. Reed's paper realizes that they are anused by enlurged cecum, described by the Germans as "mobile cecum," and are fixed mechanical conditions. When occurring in woman, with un abdomen filled with the eolon, muy a me has lost her ovaries under a diagnosis of ovarian disease when the troublo was not in the ovary at all but in the prolapsed viscern of the intestinal tract.

Dr. F. H. AlBbe, New York: Two years nigo I read before this Section a paper on the sacro-iliac joint in its relation to the pelvic organs. My attitude then held hus been confirmed. I believe that intestinal displucement is caused often by faulty posture. Our $a$-ray examinations with bismuth show us faulty position of the intestines and this produces fuulty position of the pelvie organs. This faulty posture leads to relaxation of the sucro-iliae joint. The sucro-iliac joint is sometimes so close to the pelvic organs that it is dificult to diflerentiate between puin due to displacement and that of the joint. Last yeur I was especinlly struck with the fact that two patients came to me who had been oprated on four times, and who were entirely relieved by treatment of the sucro-iliac joint. One woman stated that much to the surprise of the man who operated on her she was worse after the operation than before. The sucro-iliac joint had been still further displaced by the operation. I want to emplasize the fact that every one slould look for the relaxation or strain of this joint in the examination of the pelvis. The strain may oceur from a very simple labor or from the slightest cause. In illustration-n man helping to set a large plate glass pane leaned over holding the glass in a certain position for a few minutes and acquired this reluxation from that cause.

DR. Romen' T. Morkis, New York: I agree with Dr. Carstens. You have to go back of all these superficinl questions to the point where you are dealing with fundamental defects. Unless you realize that you are dealing with defective organs you will not grasp the subject in its entirety. You many hang up the loose colon, but how do you liang up that patient's brain? You hang up the uterus, but how do you hang up the adreinals. As Dr. Carstens says, you have to train your patient as best you can with the best organs you can bring into play. Treating one organ after another is a mistake. Tlese ptosis patients are extrenely amenable to suggestion as a class. We should go back to the fundamental fact of decadence in a rapidly developing race, when considering the eases.

Dr. Jolr N 13. Draver, Philadelphia: I endorse what Dr. Carstens and Dr. Morris lave said. I believe this question is largely one of education. If we bronght up our boys and girls to ride horsebuck, play golf, temnis, etc., fed them well and slept them well we wonld have fewer cases of ptosis. Too much attention is paid to tle training of the mind and too little to that of the body. We know that from the various boarding-schools children will come back with curvatures of the spine, with stooped shoulders; and as a matter of course, you cannot expect to find normal abdominal viscera. I see a fair percentage of these cases among shop-girls; I believe large companjes should have a gymuasium in connection with their stores and that an hour or a portion of un hour each day sliould be devoted to looking after the interests of the body. I believe that a good percentage of these cases is due to faulty parents-faulty because they know nothing about Nature or Nature's laws.

Dr. A. E. Brisamin, Minnenpolis: 1 think we are all ngreed on the etiology of the condition. If the transverse colon is fastened down to the cecum by adhesions or with adhesions around the sigmoid flexure, operation is necessany, and after operation it is essential to follow these cases for months and perhaps years. Some patients who have gone out into the country following operation lave written me that they laxve had the same symptom return. I think if we put such patients after operation in certain positions and prescribe regular forms of exercises and of diet, rlirect them to nssume the knee-chest position frequently and sleep with the foot of the bed elevated 10 or 14 inches we shall get good results. I have been able to produce permanent cures in the greater portion of these patients. Furthermore, I have been able to correct displacements of the uterus with. out operation in early cases by the sume procedure. The ptosis, the retrodisplacement and enlargement with metrorrhagia will disappear. I lave established this to $\mathrm{my}$ own sntisfuction in enough eases to know that the method is of value.

1)r. C. O. Thinenuls, Milwaukee, Wis.: It geems to me that the previous speakers are somewhat drifting away from the subject of the paper. People may have neurasthenia and lysteria without displacements of the abdominal organs, and vice versa, many women lave displacements without neuras. thenia and hysteria. Naturally, if we find that displacements or the abdominal organs are, as Charcot has expressed it, the agent provocatour of hysteria and neurasthenia, they ought to be operated on. .But 1)r. Reed's paper does not dwelt on this subject; as fur as I could understand it, he wants to point out that in many women the genital organs lave been operated on and fixed in which disenses of the intestines. such as Lane's kink, Jackson's band, movable cecum, angula. tions of the trangverse colon in the region of the spleen or liver, diseases of the sigmoid flexure, ete., were the fons et origo of the complaint. Of course, if these latter conditions produce disturbances they must be corrected; whether the. patient is suffering from neurasthenia or hysteria at the same time does not eut any figure.

Dr. Cinanies A. I. Reen, Cincinnati: Every puper that presents an innovation in trentment or a new point of view is a psychologic experiment. When it comes to the discussion you can generally tell the individual who has given that sub. ject previous thought. I an gratifed to feel that as a psychologic experiment this paper is a suceess. I think I ("ili make the classification without much difficulty. A number of those who have spoken antagonistically to the paper hatve gone wide of the mark; none has discussed it that I have heard. The point was very correctly made by Dr. Jackson that I lave not been discussing the question of the etiology of ptosis of the stomach or of the colon, or any other ptosis. That question was entirely outside of my paper. I was speaking of the relationslip of these ptoses to certain conditions in the pelves of women; and so far as the answers have been offered, only one has been made, and that by Dr. Smith, 
wl:o has rather oracularly swept the whole subject of the fuce of the earth. According to him, this relationship does not exist. It mny not exist with regard to the women of Grand Rapids, but a little farther south, in Cincinnati, we see a demonstrable comnection between these two conditions. I have a suspicion that Dr. Smith generally operates witl his patient in the Trendelenburg position, under which circumstances, of course, he never sees ptosis of the colon or of the intestine. I suspect, furthermore, that he never has an $x$-ruy picture made in his gynecologic cases. If so, he is the ouly one of my aequaintnuce who does. Without an $x$-ray picture of the position of the stomach and colon, and without a demonstration of that position at the time of the operation, Dr. Smith is really in no position to say that these conditions do not exist or do not exist with a remarkable degree of frequency. In other words, Dr. Smith has attempted to prove a negative-nways a dificult task, but especially so when the evidence is lacking.

Dr. Morris is wedded to the degeneration view of humanity. He speaks of these cases as cases of degenerucy, but we oiten find strong women who have followed a very correct hygienic life going on to 18,20 and 23 with perfectly normal functions, suddenly liuving some trauma, when all at once there is interference with metabolism concerning which Dr. Curstens seems to entertain some ratler unusual and erratic views. You cannot under these circumstances speak of this astinctly acquired and manifestly traumatic condition as one of original deseneration. I do not know where he gets lis data, but I do know that his philosophy will not fit the fucts as they occur in the clinical field.

Dr. Ricinard R. Smith, Grand Rapids, Mich.: The trouble with a discussion of this kind is that the matter is so many. sided and complicated, and the point of view so varied that the statements we make are very apt to be misapplied. T'his is evidently what has happened in the present instance. Dr. Reed quite misunderstood what $I$ said in regard to the relationship of pelvic and abdominal displacements. That they frequently coexist is unquestionable, but that they have any particular relationship is very doubtful. I have had made a very considerable number of $x$-ray examinations of patients presenting themselves with pelvic and abdominal symptoms and am quite aware of the frequency of visceral displacements. I would not wish to "sweep the thing ofr the face of the earth" as Jr. Reed las said, but I cannot too strenuously urge the necessity of eaution in the case of a woman with visceral displacements and with symptoms. We should not conclude that the two stand in the relationship of cause and effect. In the vast majority of instances at least the prtient is suffering. not because her organs are out of place, but because she las been under some strain and is fatigned or is neurotic from other causes.

\section{IODOGLYCEROLE IN THE TREATMENT OF MOUTH INFEC'TIONS *}

EUGENE S. 'TALBO'T, M.D. CHICAGo

No one drug has come into general use as a germicide. with such universal satisfaction as jodin. Its virtues are so well known in surgery as to require no comment.

I began the use of this dlug in 1878 when I commenced $m y$ researches in interstitial gingivitis. As a mouth antiseptic and germicicle it acts more quickly and more satisfactorily than any other drug. The objection to the use of the official preparation, which contains 7 per cent. iodin dissolved in alcohol to which is added 5 per cent. potassium iodid, is due to the fact that fre-

- Read in the Section on Stomatology of the American Medical Associntion, at the Slxty-Thlrd Annual Session, beld at Atlantle City, June, 1012. quent applications. will destroy the mucous membrane of the mouth. 'To obviate this, I prepared the following and called it iodoglycerole:

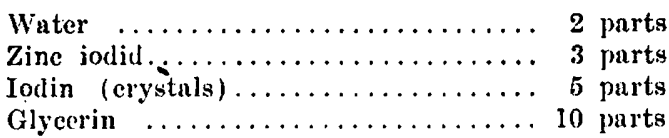

As compared with the ordinary tincture of iodin, its astringent properties are greatly increased; the glycerin causes rapid absorption and the irritating effects are reduced to a minimum. The penetrating effect is remarkable. The glycerin thickens the preparation and prevents it from mixing with the saliva and running over the mouth as the ordinary tincture will do. This prep. aration may be used on the gums every day, if necessary, without injuring the parts. The teeth as well as the sott parts of the month should be treated in like manner since all germs are destroyed. I have been able to reduce decay of the teeth in my patients in the past ten years from 30 to 40 per cent. All patients receive this treatment before or after each sitting.

Patients present themselves with fetor of the breath, pus about the teeth, inflamed gums, diseased alveolar processes, acid mucus and saliva, the latter being also ropy and stringy, plaques on the tecth and decay, with all the forms of bacteria from the most harmless to the more dangerous pathogenic microorganisms such as the pneumococcus, diphtheria bacillus, tubercle bacillus and the germs of children's diseases. Miller has demonstrated more than filty varieties of microorganisms in the mouth. Pus germs are often present in and about the necks of the teeth, and casily infect wounds and inflamed tissue. These germs are also talien into the stomach at every swallow; some pass through into the intestines and have been found in the feces. While most of the better class of patients possess fairly cleanly moutlis, yet from 12 to 20 per cent. of all patients have pus germs in the oral cavity.

Tooth decay is due to lactic-acid ferment and nearly every person has it to a greater or less extent. Clinic and dispensary patients and especially the poorer classes, who never use brushes, washes or powders in the mouth, possess regular cesspools of filth.

To prevent contagions and infections among public school children, their tecth, gums and mucous membrane should be treated with iodoglycerole as often as once a week during the school term.

What I wish particularly to call attention to is the wonderful effect this preparation has on bone disease, such as caries, necrosis, osteomyelitis and all pus surfaces such as ulcers, carbuncles, boils, ete. When applied to the bone tissue, it does not corrode and congalate, but penetrates into the tissuc, reaching the remote recesses of the cavity, and destroys the pus and other germs with which it comes in contact.

Caries of the alveolar process due to abscessed teeth yields readily after the root or roots have been amputated, often without curettement of the bone. The soothing effect of the glycerin, the astringent and stimulating properties of the zine iodid, and the germicide and antiseptic qualities of the iodin all help to restore bone tissue quickly to health.

In all operations on abscessed cavities, it should be used before as well as after operations; in extracting teeth, with or without abscess formation, it should be used before as well as after; in inflamed and diseased tonsils in which germs are always present, the preparation may be used with splendid results. 